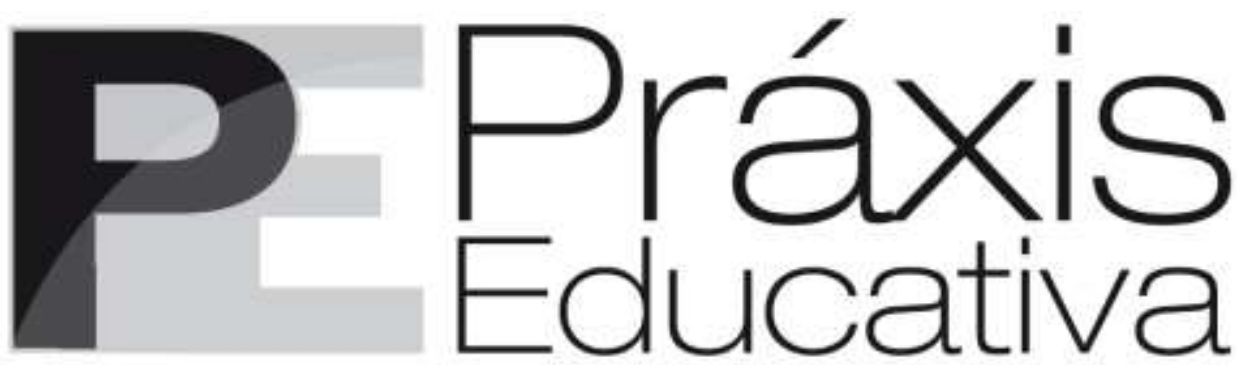

ISSN 1809-4031

elSSN 1809-4309

https://doi.org/10.5212/PraxEduc.v.17.19347.021

Dossiê: Relações étnico-raciais: práticas e reflexões pedagógicas em contextos, espaços e tempos

\title{
Para um ensino de Física afrocentrado no currículo do Ensino Médio Integrado de um Instituto Federal
}

\section{For a teaching of Physics afrocentered in the curriculum of the Integrated Middle School of a Federal Institute}

\section{Para una enseñanza de Física afrocentrada en el currículo de la Educación Secundaria Integrada de un Instituto Federal}

Jorge Ferreira Dantas Junior
(D) https://orcid.org/0000-0001-8300-3845

Resumo: Neste trabalho, foi realizada uma análise documental com o objetivo de identificar como são tratados nos currículos de Física do Ensino Médio Integrado do Instituto Federal de Educação, Ciência e Tecnologia da Bahia, campus Eunápolis, os conteúdos de História e Cultura Afro-indígena. O referencial teórico está embasado nas teorias do currículo multicultural e decolonial e na afrocentricidade, além das bases curriculares nacionais para o ensino de Física no Ensino Médio profissional. As análises indicam que, diante da predominância de cálculos e da visão eurocêntrica de construção do conhecimento científico, não há, no currículo, nada sobre filosofia e história das ciências que contemple narrativas sobre grupos historicamente marginalizados. A construção de um currículo afrocentrado e decolonial atenderá as questões legais e históricas, além de uma problematização constante entre os professores de Física.

Palavras-chave: Currículo de Física. Afrocentricidade. Decolonial.

Abstract: In this work, a documentary analysis was carried out with the objective of identifying how the contents of Afro-indigenous History and Culture are treated in the Physics curricula of the integrated High School of the Federal Institute of Education, Science and Technology of Bahia, campus Eunápolis. The theoretical framework is based on the theories of the multicultural and decolonial curriculum and on Afrocentricity, in addition to the national core standards for the teaching of Physics in secondary professional education. The analyses indicate that, given the predominance of calculations and the Eurocentric view of the construction of scientific knowledge, there is nothing, in the curriculum, about philosophy and history of science that includes narratives about historically marginalized groups. The construction of an Afro-centered and decolonial curriculum will meet legal and historical issues, in addition to a constant problematization among Physics teachers.

Keywords: Physics Curriculum. Afrocentricity. Decolonial.

* Doutor em Física pela Universidade Federal da Bahia (UFBA). Docente do Instituto Federal de Educação, Ciência e Tecnologia da Bahia (IFBA), campus Eunápolis. E-mail: <jorge.dantas@ifba.edu.br>.

Práxis Educativa, Ponta Grossa, v. 17, e2219347, p. 1-16, 2022 Disponível em: < https:// revistas2.uepg.br/index.php/praxiseducativa $>$ 
Resumen: En este trabajo fue realizado un análisis documental con el fin de identificar cómo son tratados en los currículos de Física de la Educación Secundaria del Instituto Federal de Educación, Ciencia y Tecnología de Bahía, campus Eunápolis, los contenidos de Historia y Cultura Afro-indígena. El marco teórico se basa en las teorías del currículo multicultural y decolonial, y en la afrocentricidad, además de las bases curriculares nacionales para la enseñanza de la Física en la educación profesional secundaria. Los análisis indican que, delante del predominio de cálculos y de la visión eurocéntrica de construcción del conocimiento científico, no hay, en el currículo, nada sobre filosofía e historia de las ciencias que contemple narrativas sobre grupos históricamente marginados. La construcción de un currículo afrocentrado y decolonial abordará cuestiones legales e históricas, además de una constante problematización entre los profesores de Física.

Palabras clave: Currículo de Física. Afrocentricidad. Decolonial.

\section{Considerações iniciais}

O pensar em um currículo de Física para o Ensino Médio no Brasil surgiu, ao longo dos anos, por influência de pesquisas na área e problematização no contexto escolar. Orientações curriculares nacionais vêm contribuindo de forma mais reflexiva, interdisciplinar e, às vezes, integrada e menos tradicional. Nesse contexto, com a aprovação da Lei $\mathrm{N}^{\circ} 10.639$, de 9 de janeiro de 2003 (BRASIL, 2003) e da Lei No 11.645, de 10 março de 2008 (BRASIL, 2008a), que alteram a Lei No 9.394, de 20 de dezembro de 1996 (BRASIL, 1996) - Lei de Diretrizes e Bases da Educação Nacional (LDB) -, para a obrigatoriedade do ensino de História e Cultura Afro-brasileiras, Africanas e Indígenas em toda rede de Ensino Médio, surge, também, a necessidade de se repensar a formação do próprio licenciado que deverá estar apto para introduzir no currículo do ensino de Física diversos saberes, não se limitando aos conhecimentos eurocêntricos. Para isso, é necessário que esses profissionais tenham a formação que viabilizem não apenas as aulas teóricas, mas também as práticas que busquem por aprendizagens que envolvam, também, saberes afrocentrados (SILVA; CORENZA, 2018).

Dificuldades são encontradas por grande parte dos professores de Física em incorporar os conteúdos exigidos na Lei $\mathrm{N}^{\circ}$ 10.639/2003 (BRASIL, 2003) e na Lei $\mathrm{N}^{\circ}$ 11.645/2008 (BRASIL, 2008a) em suas práticas em sala de aula. Isso porque, em muitos casos, eles não tiveram em sua formação inicial tal conteúdo, pois o histórico de formação docente e o ensino eram muito mais voltados "[...] ao formalismo matemático e conteúdos conceituais e menos foco para a ciência enquanto prática social, de maneira mais humanizada" (SANTOS; ALEM; DANTAS JR., 2018, p. 4), o que os fazem resistir para o trato com epistemologias historicamente desprivilegiadas no espaço educacional. Além do mais, as práticas pedagógicas dos professores são bem enraizadas. Como citam Furió et al. (2001),

[...] os professores têm ideias, comportamentos e atitudes com respeito a diferentes aspectos relacionados ao processo de ensino e aprendizagem devidos a uma longa formação "ambiental" durante o período em que foram alunos, e em sua própria prática docente, já que respondem a experiências que se repetiram durante anos e que foram adquiridas como algo óbvio, como algo natural, e que se converte em um verdadeiro obstáculo quando se pretende renovar o processo de ensino e aprendizagem. (FURIÓ et al., 2001, p. 368).

Não podemos negar a evidente dificuldade por parte dos professores e das instituições escolares em implementar uma reformulação curricular com o intuito de introduzir em suas matrizes as relações étnico-raciais, como sugerem as Diretrizes Curriculares Nacionais para a Educação das Relações Étnico-Raciais e para o Ensino de História e Cultura Afro-Brasileira e Africana ao afirmarem que não é fácil descender de humanos escravizados que foram tratados como objetos utilitários, porém é mais difícil se descobrir descendente dos negros escravizados e temer, veladamente, uma possível revanche dos 500 anos de massacres (BRASIL, 2004). E o texto continua:

Práxis Educativa, Ponta Grossa, v. 17, e2219347, p. 1-16, 2022 Disponível em: < https://revistas2.uepg.br/index.php/praxiseducativa $>$ 
Para reeducar as relações étnico-raciais, no Brasil, é necessário fazer emergir as dores e medos que têm sido gerados. É preciso entender que o sucesso de uns tem o preço da marginalidade e da desigualdade impostas a outros. E então decidir que sociedade queremos construir daqui para frente. (BRASIL, 2004, p. 14).

Diante de que foi dito até o momento, este trabalho tem como intuito fazer uma análise documental dos currículos de Física do curso Técnico em Edificações Integrado ao Ensino Médio do Instituto Federal de Ciência, Tecnologia e Educação da Bahia (IFBA) do campus Eunápolis, para identificarmos como estão sendo tratados os conteúdos de História e Cultura Afro-brasileira, Africanas e Indígenas, utilizando as teorias do currículo multicultural e afrocentrada.

\title{
Um (outro) olhar sobre a construção de um currículo de Física para o Ensino Médio Integrado ao Técnico
}

Como consta no Art. $2^{\circ}$ da Resolução No 6, de 20 de dezembro de 2012 (BRASIL, 2012), que define as Diretrizes Curriculares Nacionais pra Educação Profissional Técnica de Nível Médio, a Educação Profissional e Tecnologia, nos termos da Lei N 9.394/1996 (LDB) (BRASIL, 1996), alterada pela Lei $\mathrm{N}^{\circ}$ 11.741, de 16 de julho de 2008 (BRASIL, 2008b), figuram aos Institutos Federais como uma instituição de Ensino Superior, equiparada às Universidades, pois procura articular "[...] educação superior, básica e profissional, pluricurricular e multicampi, especializada na oferta da educação profissional e tecnológica em diferentes níveis e modalidade de ensino" (BRASIL, 2010, p. 18)

A Lei No 11.892, de 29 de dezembro de 2008 (BRASIL, 2008c), que cria os Institutos Federais, estabelece, em seu Art. $7^{\circ}$, a obrigatoriedade dessas instituições em ofertar educação profissional e tecnológica em todos os níveis de ensino, priorizando uma razão de $50 \%$ na forma de cursos técnicos de nível médio integrado, para os concluintes do Ensino Fundamental e para o público da Educação de Jovens e Adultos (EJA).

Inserir as disciplinas do núcleo comum, como exemplo Língua Portuguesa, Matemática e Ciências da Natureza, e integrá-las na construção do projeto do curso para que se configure em um processo de ação global é um desafio. Nesse sentido, Ciavatta (2012) fala da importância e da necessidade de se fazer uma educação profissional integrada:

\begin{abstract}
A ideia de formação integrada sugere superar o ser humano dividido historicamente pela divisão social do trabalho entre a ação de executar e a ação de pensar, dirigir ou planejar. Trata-se de superar a redução da preparação para o trabalho ao seu aspecto operacional, simplificado, escoimado dos conhecimentos que estão na sua gênese científicotecnológica e na sua apropriação histórico-social. Como formação humana, o que se busca é garantir ao adolescente, ao jovem e ao adulto trabalhador o direito a uma formação completa para a leitura do mundo e para a atuação como cidadão pertencente a um país, integrado dignamente à sua sociedade política. Formação que, nesse sentido, supõe a compreensão das relações sociais subjacentes a todos os fenômenos. (CIAVATTA, 2012, p. 85).
\end{abstract}

O componente curricular de Física tem evoluído no decorrer dos anos, e, para discutir a sua inserção no currículo escolar, é preciso romper certas barreiras que vão além de apenas elencar conteúdos a serem abordados, uma vez que a própria definição "o que", "para quem" e "por que" ensinar suscita um projeto de sociedade que defendemos e de visões de mundo adotadas pelos agentes que construirão esse currículo.

Assim como é discutido por Silva (2010, p. 15), o currículo “[...] é sempre o resultado de uma seleção: de um universo mais amplo de conhecimentos e saberes" e que são as teorias do currículo que darão suporte para justificar "por que esses conhecimentos" e não "aqueles" que

Práxis Educativa, Ponta Grossa, v. 17, e2219347, p. 1-16, 2022 Disponível em: < https://revistas2.uepg.br/index.php/praxiseducativa> 
deveriam ser selecionados, estando atrelado o que esperamos do indivíduo imerso na proposta: "o que eles/elas devem ser?( ou se tornar?)". Em outras palavras:

\begin{abstract}
Qual o tipo de ser humano desejável para um determinado tipo de sociedade? Será uma pessoa racional e ilustrada do ideal humanista de educação? Será a pessoa otimizadora e competitiva dos atuais modelos neoliberais de educação? Será a pessoa ajustada aos ideais de cidadania do moderno estado-nação? Será a pessoa desconfiada e crítica dos arranjos sociais existentes preconizada nas teorias educacionais críticas? A cada um desses "modelos" de ser humano corresponderá um tipo de conhecimento, um tipo de currículo. (SILVA, 2010, p. 15).
\end{abstract}

Em pesquisas sobre eduação, alguns teóricos se dedicam a analisar mais profundamente o currículo do Ensino Médio Integrado ao Técnico, seu caminho e suas implicações no contexto do país. Esses estudos estão evidentes no texto Ensino Médio Integrado: concepções e contradições, de Ramos, Frigotto e Ciavatta (2012), bem como em documentos governamentais, alguns sintetisados em livros como em Pacheco (2012) que contextualiza o Ensino Médio Integrado ao Técnico e discute atualizações nas Diretrizes Curriculares Nacionais para a educação técnica de nível médio. Concomitante aos estudos do currículo do Ensino Médio Integrado ao Técnico das disciplinas do núcleo comum, pesquisadores de educação em ciências vêm intensificando suas pesquisas no âmbito do currículo, sendo este último incorporado em linhas temáticas em importantes eventos de ensino de Física.

Nesse contexto, ressaltamos a plublicação da Sociedade Brasileira de Física (SBF) intitulada Enfrentamentos do ensino de Física na sociedade contemporânea (GARCIA; AUTH; TAKAHASHI, 2016), que ocorreu no XXI Simpósio Nacional de Ensino de Física (SNEF) em 2015, como resultado das “[...] reflexões e ações colaborativas entre os pesquisadores e entusiastas pelo ensino e aprendizagem em Física, voltadas principalmente às demandas da área" (GARCIA; AUTH; TAKAHASHI, 2016, p. 11) no que tange ao cenário educacional brasileiro atual.

Portanto, neste estudo, utilizaremos os teóricos dos currículos e as Diretrizes Curriculares Nacionais para a educação técnica de nível médio como suleadores para analizarmos o currículo de Física para o Ensino Médio Integrado ao Técnico do curso de edificações do IFBA, campus Eunápolis, dando ênfase ao modelo de Ensino Médio técnico na forma integrada e os princípios gerais para um currículo afrocentrado.

\title{
O que quer um currículo de Física negro?
}

As relações étnico-raciais introduzidas na educação brasileira é marcada por muitas lutas, principalmente pelos Movimentos Sociais Negros e a Lei No 10.639/2003 que faz com que todos os estabelecimentos de ensino sejam obrigados a incluir como tema, nos componentes curriculares, a História e Cultura Africana e Afro-brasileira (BRASIL, 2003). Como afirma Gomes (2003), o objetivo de se discutir sobre cultura negra no ensino consiste em ressignificar e construir representações positivas sobre o negro, sua história, cultura e sua estética. Seguindo esse raciocínio, Santos, Alem e Dantas Jr. (2018) nos dizem:

Para além de força de lei e diretrizes o ensino da Cultura e História Africana e Afrobrasileira, assim como a incorporação das histórias e culturas dos povos indígenas com a Lei n. ${ }^{\circ}$ 11.645/08 representam a necessidade de superar as mazelas históricas que o silenciamento dos conteúdos referentes a estes povos causou na sociedade brasileira. Isso porque os sistemas educacionais em geral, apesar de alguns avanços, normatizam o discurso pedagógico, que se propõe didático, baseado no etnocentrismo. Com essa prática, invisibilizam de seus currículos as formas de vida produzidas pela interação entre as diferentes culturas que compõem a nação brasileira, deixando a responsabilidade aos estudantes negros e indígenas a luta por sua própria emancipação intelectual e social,

Práxis Educativa, Ponta Grossa, v. 17, e2219347, p. 1-16, 2022 Disponível em: < https://revistas2.uepg.br/index.php/praxiseducativa $>$ 
naturalizando um modelo de educação que não contempla a diversidade humana. (SANTOS; ALEM; DANTAS JR., 2015, p. 5).

Para compreendermos o que seria um currículo negro, devemos entender o que significa uma educação afrocentrada e quais os seus fundamentos. De acordo com Santos Junior (2010, p. 2), o exame desses " [...] fundamentos remete para a apresentação dos principais elementos para um currículo afrocentrado, além da articulação destes com as Diretrizes Curriculares Nacionais para Educação das Relações Etnicorraciais e para o Ensino de História e Cultura Afrobrasileira e Africana [...]". O autor afirma, ainda, que devemos, antes de tudo, caracterizar a afrocentricidade, e cita o professor Molefi Asante que sintetizou a afrocentricidade na década de 1980. Segundo Asante (2009b, p. 93): “A afrocentricidade é um tipo de pensamento, prática e perspectiva que percebe os africanos como sujeitos e agentes de fenômenos atuando sobre sua própria imagem cultural e de acordo com seus próprios interesses humanos". Asante (2009b) afirma que a afrocentricidade surge como conscientização política de uma população que estava à margem da produção educacional, econômica e tecnológica tal como são definidas pelos interesses eurocêntricos. Para o autor, o cerne da afrocentricidade está na conscientização, o que é totalmente diferente de africanidade, visto que se pode praticar os usos e os costumes africanos sem ser afrocêntrico: "Afrocentricidade é a conscientização sobre a agência dos povos africanos" (ASANTE, 2009b, p. 94).

É importante deixarmos evidente que a afrocentricidade não significa que seja uma versão negra em contraponto ao eurocentrismo branco (ASANTE, 1991). A afrocentricidade condena a visão etnocêntrica, em que tudo que se produz (e produziu) de conhecimento da humanidade é por conta da "evolução" dos povos europeus (brancos) em detrimento de outros povos (não-brancos). O reflexo dessa "verdade universal" é imposta por uma sociedade educada nos preceitos eurocêntricos, que muitos acadêmicos, políticos e artistas afrodescendentes negam sua negritude, acreditando que ser negro é negar uma humanidade universal. Por consequência de um colonialismo enraizado em nossa sociedade, essas pessoas acreditam que tudo que é melhor produzido e interessante se origina na Europa, em detrimento das produções de seu próprio povo (ASANTE, 1991).

A afrocentricidade tem a ver com a questão de localização do sujeito, pois historicamente são os não-negros que são deslocados do centro para margem da experiência eurocêntrica. "[...] todas as relações são baseadas em centros e margens e nas distâncias de cada lugar do centro ou da margem" (ASANTE, 2009a, n.p., tradução nossa). Portanto, para tentar-se construir um currículo negro, deve-se prestar atenção na localização psicológica e/ou cultural. Segundo Asante (2009b):

Para o afrocentrista a análise de uma pessoa com frequência se relaciona com o lugar onde sua mente está situada. Por exemplo, normalmente é possível determinar se uma pessoa está localizada em uma posição central em relação ao mundo africano pelo modo como ela se relaciona com a informação africana. Se ela se refere aos africanos como "outros", percebemos que os vê como diferentes de si mesma. Essa é uma das formas pelas quais funciona o deslocamento. Evidentemente, se a pessoa não é africana, mas tenta fazer uma análise afrocêntrica, o que se observa é sua capacidade de olhar os fenômenos do ponto de vista dos próprios africanos. (ASANTE, 2009b, p. 96).

Utilizando os conceitos de currículo e de afrocentricidade, precisamos buscar pesquisadores que contribuam com novos conceitos e conteúdos apoiados na história e na filosofia dos povos africanos (SANTOS JUNIOR, 2010). Dentre os pesquisadores (cientistas, filósofos e historiadores) negros que buscaram e buscam contribuir para a divulgação de uma ciência afrocentrada, destacamos os trabalhos de Cheick Anta Diop e Carlos Machado, que servem de base para a construção de um olhar crítico a respeito dos conteúdos a serem trabalhados no ensino de Física, pois abordam temas como matemática, metalurgia, engenharia e astronomia.

Práxis Educativa, Ponta Grossa, v. 17, e2219347, p. 1-16, 2022 Disponível em: < https://revistas2.uepg.br/index.php/praxiseducativa $>$ 
Cheik Anta Diop era físico, matemático, químico, historiador, egiptólogo e antropólogo, linguista, sociólogo e ativista político. Em seu artigo Contribuição da África para a civilização mundial: As Ciências Exatas, de 1985, ele relata a ciência que os povos africanos faziam muito tempo antes dos europeus. Os egípcios foram capazes de calcular o volume de uma pirâmide, o volume de um cilindro e a área de superfície de um hemisfério com um valor de pi $(\approx 3,16)$ com uma precisão muito próximo do valor atual $(\approx 3,14), 1700$ anos antes de Arquimedes (MACHADO, 2014).

Além de serem capazes de calcular raiz quadrada, usaram números imaginários, inventaram a trigonometria e o "teorema de Pitágoras" antes de Pitágoras. No campo da Física, os egípcios utilizavam o plano inclinado, alavanca, parafusos, sifões para transferência de líquidos, além do conhecimento de pressão do ar. Não foi coincidência que grandes filósofos como Aristóteles, Sócrates e Platão estudaram extensivamente no Egito (MACHADO, 2014).

$\mathrm{Na}$ astronomia, os egípcios constataram, há mais de quatro milênios, que a estrela Sirius se encontrava na mesma posição que o Sol nascia a cada 1461 anos. A relevância de estudar a posição da estrela Sirius para os egípcios deve-se ao fato de que ela assinalava a data mais importante para eles, pois, quando ela aparecia ao Leste, anunciava a enchente do Rio Nilo, fertilizava os campos assegurando colheita farta (CUNHA, 2005).

Podemos citar como outro exemplo de conhecimento astronômico dentro da África, a contribuição dos antigos africanos da nação do Dogon (região do antigo Mali), os quais já sabiam da existência de um "pequenino" satélite da estrela Sirius, conhecida hoje como de Sirius B, que é invisível a olho nu, e reproduziam em desenho sua trajetória que confere com dados astronômicos modernos (CUNHA, 2005).

No período de um ano, Sirius B roda uma vez em torno de seu próprio eixo, evento celebrado pelos Dogon com o festival bado. Esta rotação ainda não é conhecida dos astrônomos modernos, que, no entanto, já confirmaram a órbita de cinquenta anos que os Dogon constataram para outra estrela que órbita Sirius. (CUNHA, 2005, p. 8).

Interessante também citar a única cientista do sexo feminino na história por 15 séculos, Hypatia de Alexandria. Ela não era grega, mas, sim, egípcia, portanto de origem africana, e permaneceu solteira e trabalhou livre e publicamente fazendo pesquisas e palestras sobre Matemática, Filosofia, Física e Astronomia. Além de escrever tratados sobre álgebra, é creditada a ela a criação do astrolábio e o hidrômetro (MACHADO, 2014).

Imhotep, egípcio, foi o primeiro arquiteto, engenheiro e médico da antiguidade. Foi responsável por construir a pirâmide de Saqqara entre 2630 e 2611 a.C. com enormes degraus que atingiam aproximadamente 62 metros, sendo considerado o mais antigo edifício de pedra do mundo. Projetos outros de pirâmide não se comparavam ao feito por Imhotep, pois os degraus pareciam mais com bancos de pedra empilhados (MACHADO, 2014).

Para a construção de um currículo afrocentrado, Santos Junior (2010) traça estratégias para a inclusão de elementos afrocêntricos na disciplina de Física:

A disciplina de Física pode ser uma das responsáveis pelo estudo de seus conceitos através da confecção de instrumentos musicais africanos, tal como a kalimba, o djembê, o dundu, kisanji, analisando o tema de ondas mecânicas e acústicas, o trabalho pode ser integrado com Educação Artística que pode trabalhar na construção desses instrumentos. Por exemplo, a disciplina de Física pode estudar as ondas da kalimba, enquanto esse instrumento pode ser analisado na aula de Educação Artística, a partir de sua afinação pentatônica e ser construída. (SANTOS JUNIOR, 2010, p. 9).

Práxis Educativa, Ponta Grossa, v. 17, e2219347, p. 1-16, 2022 Disponível em: < https:// revistas2.uepg.br/index.php/praxiseducativa $>$ 
Representatividade também é importante ao se pensar um currículo afrocentrado. Destacamos a história de Lewis Howard Latimer descrita por Morais (2017) em um artigo intitulado Lewis Howard Latimer e sua história aprisionada, que coloca o nome de Latimer, um negro, entre os grandes inventores e engenheiros do seu tempo, como Thomas Edison e Nikola Tesla.

Temos de considerar que um currículo de Física vai além do planejamento de aula do professor, perpassa pelo livro didático. Em uma análise do livro didático de Física para o Ensino Médio, Santos, Alem e Dantas Jr. (2018) analisam a coleção "Compreendendo a Física, Alberto Gaspar - 3. ed. - São Paulo: Ática, 2016”, que foi adotada pelo IFBA, Campus Eunápolis no último edital do Programa Nacional do Livro Didático (PNLD), no ano da publicação do artigo, e verificaram que, no geral, não havia nenhuma menção sobre a história científica do povo negro nem a contribuição deles para o conhecimento da humanidade. Segundo os autores, o material foi todo construído baseado na visão eurocêntrica, não contemplando a Lei $\mathrm{N}^{\circ}$ 10.639/2003 (BRASIL, 2003) e a Lei N $11.645 / 2008$ (BRASIL, 2008a). Isso fica evidente ao observarmos as figuras que ilustram as obras nos exemplos e nas questões dos livros, visto que a maioria das pessoas é apresentada com estereótipo branco eurocêntrico.

Cunha (2005, p. 4) lembra que as “[...] grandes distorções históricas a respeito do legado cultural e científico dos povos africanos e afrodescendentes resultam principalmente da predominância do eurocentrismo na história oficial". O autor cita também que:

\begin{abstract}
A negação do passado científico e tecnológico dos povos africanos e a exacerbação do seu "caráter lúdico" foi uma das principais façanhas do eurocentrismo e que ainda hoje abala fortemente a autoestima da população africana e da diáspora, pois os "métodos", "conceitos" e muitos cientistas europeus deram a impressão ao restante do mundo, de que as populações africanas não tiveram uma contribuição relevante para a construção do conhecimento universal. Isso fica bastante evidente em vários trabalhos de pesquisas empreendidos por cientistas preconceituosos que descreveram a África como um continente eternamente pré-histórico, bárbaro, cujos habitantes, no geral, se apresentam como seres bestiais, incapazes de construir ou transmitir conhecimentos relevantes. (CUNHA, 2005, p. 5).
\end{abstract}

Podemos observar, com o que foi demonstrado até o momento, que é possível ensinar conteúdos de Física elaborados a partir de um currículo afrocentrado, de modo a contribuir para a efetivação da Lei $\mathrm{N}^{\circ}$ 10.639/2003 e destacar a história que foi negada, por vezes silenciada, e quase totalmente apagada, dos feitos dos povos africanos na área da ciência como um todo.

\title{
O currículo do ensino de Física nos cursos de Ensino Médio Integrado ao Técnico do Instituto Federal da Bahia - campus Eunápolis
}

O objeto de estudo deste artigo é o componente de Física do curso de Ensino Médio Integrado ao Técnico de Edificações do IFBA, campus Eunápolis. Por ser docente e pesquisador desse instituto e comprometido com a produção de conhecimento interdisciplinar e integrado, compreendemos a relevância da reflexão sobre o planejamento curricular na ação docente.

Entendemos a importância de repensar um currículo de forma inclusiva e crítica, com uma visão afrocentrada, decolonial e multicultural, com o intuito de quebrar paradigmas, dando destaque à historiografia do negro africano no Brasil e resgatando, de forma positiva, a presença negra em nossa sociedade, longe do olhar castrador do colonizador que creditou ao afro-brasileiro a posição de menor, selvagem, bárbaro e inferior no mundo europeu (SILVA, 2014).

O Projeto Pedagógico do Curso (PPC) Técnico de Edificações Integrado ao Ensino Médio do IFBA, campus Eunápolis (IFBA, 2011), que foi reformulado em 2011, possui carga horária de

Práxis Educativa, Ponta Grossa, v. 17, e2219347, p. 1-16, 2022 Disponível em: < https://revistas2.uepg.br/index.php/praxiseducativa $>$ 
4.392 horas-aula, com estágio de 240 horas, totalizando a carga horária que equivale a 3.900 horas, dividido em quatro anos.

A matriz curricular está de acordo com as competências e habilidades específicas e gerais, considerando a Resolução $N^{\circ}$ 4, de 8 de dezembro de 1999 (BRASIL, 1999), da Câmara de Educação Básica do Conselho Nacional de Educação (CEB/CNE), sendo dividida em Base Nacional Comum, Parte Diversificada e Formação Específica, como podemos ver nos Quadros 1, 2 e 3.

Quadro 1 - Matriz curricular

\section{Base Nacional Comum}

Linguagens, Códigos e suas Tecnologias: Língua Portuguesa, Educação Física e artes

Ciências Humanas e suas Tecnologias: História, Geografia e filosofia

Ciências da Natureza, Matemática e suas Tecnologias: Física, Matemática, Biologia, Química e

Desenho Básico

Fonte: Elaborado pelo autor com base em IFBA (2011).

Quadro 2 - Matriz curricular

\begin{tabular}{|l|}
\multicolumn{1}{|c|}{ Parte Diversificada } \\
\hline Organização do Trabalho e Gestão de qualidade (ONQ) \\
\hline Língua Estrangeira Moderna - Inglês \\
\hline Língua Estrangeira Moderna - Espanhol (Optativa) \\
\hline Sociologia \\
\hline Segurança do Trabalho, Meio Ambiente e Saúde (SMS) \\
\hline Informática Aplicada \\
\hline
\end{tabular}

Fonte: Elaborado pelo autor com base em IFBA (2011).

Quadro 3 - Matriz curricular

\begin{tabular}{|l|l|}
\hline \multicolumn{2}{|c|}{ Formação Específica } \\
\hline Materiais de Construção I & Instalações Hidrossanitárias \\
\hline Materiais de Construção II & Saneamento Básico \\
\hline Desenho Arquitetônico I & Mecânica dos Solos \\
\hline Desenho Arquitetônico II & Planejamento e Gerenciamento de Obras \\
\hline Resistência dos Materiais & Tecnologias da Construção I \\
\hline Estruturas & Tecnologias da Construção II \\
\hline Instalações Elétricas & Topologia \\
\hline
\end{tabular}

Fonte: Elaborado pelo autor com base em IFBA (2011).

O projeto menciona a integração que deve existir no curso e espera um perfil de egresso que contemple não apenas o conhecimento técnico, mas também ao do núcleo comum, porém falta uma menção de como poderá ocorrer a articulação formativa da área técnica com o núcleo. Além disso, não deixa evidente quando lista as necessidades de desenvolvimento de sete competências na formação do indivíduo:

\footnotetext{
- Dominar a leitura, a escrita e as diversas linguagens utilizadas pelo homem;

- Fazer cálculos e resolver problemas;

- Analisar, sintetizar e interpretar dados, fatos e situações;

- Compreender seu entorno social e atuar sobre ele;

- Receber criticamente os meios de comunicação;

- Localizar, acessar e usar melhor a informação acumulada;

- Planejar, trabalhar e decidir em grupo. (IFBA, 2011, p. 12).
}

Práxis Educativa, Ponta Grossa, v. 17, e2219347, p. 1-16, 2022 Disponível em: < https://revistas2.uepg.br/index.php/praxiseducativa $>$ 
O item "Compreender seu entorno social e atuar sobre ele" não deixa evidente como essa compreensão será tratada, já que, ao longo do texto, não há mais nenhuma menção sobre esse item, deixando passar uma excelente oportunidade para se debruçar sobre o tema étnico-racial em que esse indivíduo está inserido - não apenas como integrante de um grupo social, mas como um agente que não só deva compreender seu entorno social, mas que interaja de forma positiva sobre ele.

No texto sobre o perfil do egresso, há a menção à palavra "alteridade", que também seria um momento para uma discussão e efetivação no projeto da promoção da igualdade racial. Contudo, o texto não avança nesse sentido, como podemos observar a seguir:

Como premissa básica, almeja-se formar um cidadão com capacidade de analisar, decidir, planejar e expor suas ideias ao mundo em que se insere. É o reconhecimento da alteridade, de que o indivíduo deve estar preparado, fundamentalmente, para interagir com o outro, levando valores e conceitos e absorvendo valores e conceitos. Nesse contexto, o conhecimento é uma via de mão dupla, de constante movimento de idas e vindas, um moto contínuo. E o papel das instituições de ensino é de promover ao profissional a possibilidade de ir e vir, estar apto e aberto ao conhecimento, sempre. (IFBA, 2011, p. 12).

O curso de edificações é dividido em quatro anos, dos quais o componente curricular Física é ministrada nos três primeiros, com carga horária de 324 horas-aulas, que equivalem a 180 horas.

Ao analisarmos a Ementa de Física ${ }^{1}$ do $1^{\circ}$ ao $3^{\circ}$ ano do Curso Técnico em Edificações Integrado ao Médio, observamos, na seção "Competências e Habilidades" (Figuras 1, 2 e 3), que a preocupação é que o aluno possa compreender os códigos e símbolos físicos, discriminar e traduzir as linguagens matemáticas e discursivas. Não que essas competências e habilidades não sejam relevantes para o curso, mas apenas no último tópico, da ementa do $1^{\circ}$ ano, que há uma "tentativa" de tornar o currículo menos tecnicista ao afirmar que uma das habilidades é "descobrir como funcionam os aparelhos", limitando o conceito de Física e sociedade a uma mera compreensão do funcionamento de um equipamento doméstico.

A visão tecnicista continua no que tange aos conteúdos programáticos das três ementas (ver Figuras 1, 2 e 3). Não há nenhum tópico sobre a Física utilizada por outros povos, como, por exemplo, os egípcios que, além do conhecimento sobre engenharia e matemática (mais de 1000 anos antes dos europeus), possuía um conhecimento sobre astronomia extremamente avançada para a sua época.

\footnotetext{
1 Tanto as matrizes de Física quanto o PPC do curso técnico em edificações integrado ao Ensino Médio podem ser vistos em http://portal.ifba.edu.br/eunapolis/documentos-ads/plano-de-curso-edificacoes-integrado-1.pdf. Acesso em: 17 jan. 2022.
} 
Para um ensino de Física afrocentrado no currículo do Ensino Médio Integrado de um Instituto Federal

Figura 1 - Ementa de Física do $1^{\circ}$ ano do Curso

Técnico em Edificações Integrado ao Médio do IFBA/Eunápolis

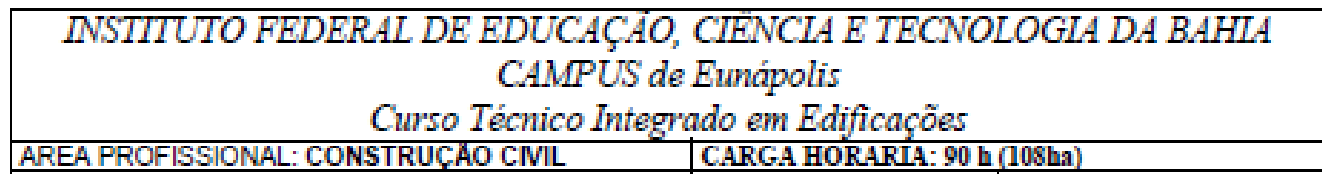

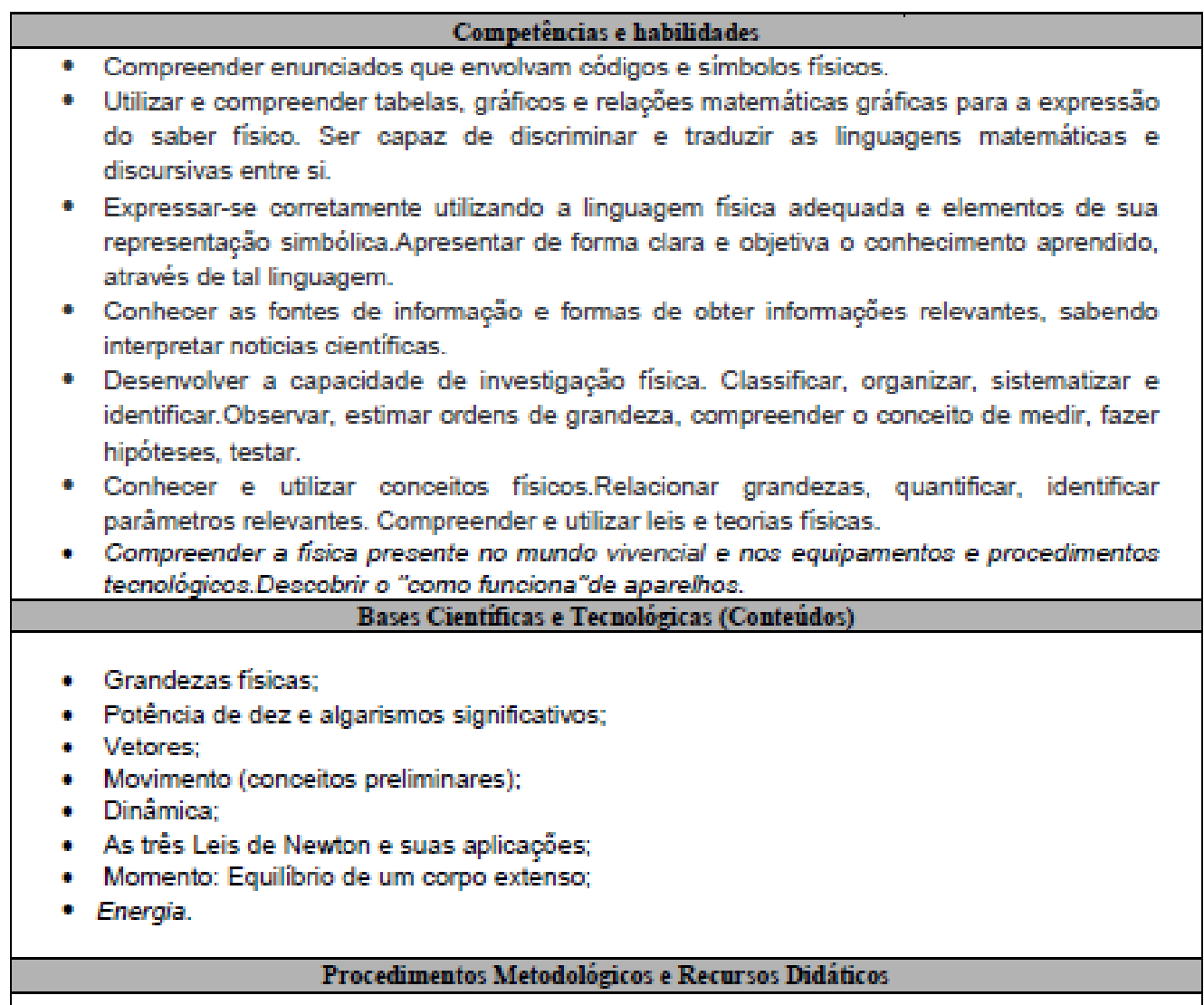

Fonte: IFBA (2011, p. 32).

Além disso, o conteúdo programático nas três séries foi feito de forma muito reduzida. Conceitos importantes para uma formação do conhecimento em Física foi deixado de fora, como, por exemplo, a gravitação e o lançamento de corpos. No que diz respeito à obrigatoriedade da Lei No 10.639/2003 (BRASIL, 2003), não existe nenhuma menção sobre a produção científica e tecnológica da população negra - lembrando que o projeto foi reformulado em 2011, oito anos após a implementação da lei. O mesmo se aplica em relação à Lei $\mathrm{N}^{\circ}$ 11.645/2008 (BRASIL, 2008a), que alterou a Lei No 10.639/2003 (BRASIL, 2003), incluindo a valorização da cultura indígena e afro-brasileira.

Práxis Educativa, Ponta Grossa, v. 17, e2219347, p. 1-16, 2022 Disponível em: <https:// revistas2.uepg.br/index.php/praxiseducativa> 
a tentativa de determinados grupos em minimizar a predominância europeia chamando o eurocentrismo de "simples etnocentrismo".

O projeto de curso em análise não cumpre o papel legal, nem para além dele, no que tange à promoção da igualdade racial curricular na escola - uma problemática muito comum ainda nas instituições de ensino, mesmo depois de mais de dez anos da lei efetivada. Essa reflexão precisa ser operacionalizada em mudanças sistemáticas nos currículos escolares e acionada nas práticas pedagógicas.

\section{Considerações finais}

Neste artigo, fizemos uma reflexão sobre o currículo de Física do Curso Técnico em Edificações Integrado ao Médio do Instituto Federal de Educação, Ciências e Tecnologia da Bahia, campus Eunápolis, em busca de promover a igualdade racial e a diversidade étnico-racial e lançar mão de uma agenda afrocentrada, com o intuito de empreender uma educação antirracista, inclusiva, reparadora e emancipatória e de valorizar conhecimentos de povos africanos que outrora foram negados e jogados à margem da construção do currículo de Física do Ensino Médio.

A construção de um currículo negro para o ensino de Física vai além do conteúdo científico da disciplina e das teorias decoloniais e afrocentradas. É um trabalho constante e diário de desconstrução de conceitos eurocêntricos enraizados em nossa cultura. A resistência dos profissionais da área de Física em sair de sua "bolha tecnicista" e perceber que o ensino de Física vai além de descrever a natureza e seus fenômenos, faz com que esse pensamento seja transferido para o currículo, propagando essa forma de agir/pensar na vida do estudante. É preciso perceber que a história da ciência e dos povos que ajudaram na sua construção não pode ser negligenciada ou omitida em detrimento de uma ideia de "ciência verdadeira" e "elitizada", com suas verdades incontestáveis. Segundo Machado (2014), John Pappademos, no livro Síntese Newtoniana em Ciências Físicas e suas Raízes no Vale do Nilo, de 1985, sustenta que

[...] o trabalho de Newton foi baseado no trabalho em matemática, astronomia e mecânica, que foi iniciada em tempos antigos. Isso levou a ciência egípcia que por sua vez influenciaram os cientistas como Kepler, Copérnico, Galileu, Descartes e que por sua vez serviu de base para o trabalho de Newton. (MACHADO, 2014, p. 37).

É necessária, portanto, a luta por diferentes modos e espaços contra a depreciação da população negra de forma a visibilizar a cultura africana, afro-brasileira, indígena, mestiça e ameríndia. Entendemos que os elementos que dão sustentabilidade à Escola atuam com um microcosmo da sociedade, com todo o seu poder de interferir e de influenciar na formação dos estudantes e nos seus posicionamentos frente ao mundo (SANTOS; ALEM; DANTAS JR., 2018). Assim,

[...] uma proposta de educação afrocentrada deve estar assentada em fundamentos apoiados na história dos povos africanos, numa linha filosófica africana, em investigações sociológicas que analisem as sociedades africanas e afrodiaspóricas, e, numa psicologia afrocentrada. É fundamental que todo projeto afrocentrado de educação perceba como o sistema educacional hegemônico é permeado, constituído e divulgador desses valores que localizam a natureza como objeto, o conhecimento como arma e propriedade, e, o ser humano como ser que "controla" e exige que tudo gravite ao seu redor. Mas, não se

\footnotetext{
2 "Fenômeno universal que expressa a tendência de um indivíduo ou grupo bumano em pautar a compreensão do mundo a partir do seu ponto de vista, centro ou referência." (CUNHA, 2005, p. 4, grifo do autor).

3 O termo "bolha tecnicista" está sendo empregado para indivíduos que compartilham as mesmas ideias, os mesmos valores e conhecimentos, julgando de forma preconceituosa aqueles que não fazem parte desse núcleo.
}

Práxis Educativa, Ponta Grossa, v. 17, e2219347, p. 1-16, 2022 Disponível em: < https://revistas2.uepg.br/index.php/praxiseducativa $>$ 
trata, somente, de identificar os padrões hegemônicos; mas, de propor e sustentar a afrocentricidade. É preciso conceber a natureza a partir de um lugar africano em todos os aspectos da vida. (SANTOS JUNIOR, 2010, p. 6).

Não temos como desassociar a ciência da sociedade que ela está inserida. A ciência reflete a cultura de um povo e faz parte da sua construção social, pois está sujeita às mesmas mazelas que atingem a sociedade como um todo; por conta disso, não está imune às tensões étnico-raciais (ROSA, 2016). Por isso, a importância de discutir-se o currículo de Física no contexto étnico-racial e suas implicações. A Lei No 10.639/2003 (BRASIL, 2003) convoca os professores a se debruçarem sobre a educação das relações étnico-raciais, pois precisam estar preparados para "[...] lidar com as tensas relações produzidas pelo racismo e discriminações [...] entre diferentes grupos étnico-raciais" (BRASIL, 2004, p. 4). A construção do currículo de Física precisa romper com a estrutura cientificista, eurocêntrica e ocidental para uma proposta curricular que se efetive por meio das agendas dos movimentos sociais, em especial, do povo negro.

\section{Referências}

ASANTE, M. K. Afrocentric idea in education. The Journal of Negro, [s. l.], v. 60, n. 2, p. 170180, 1991. Disponível em: https://www.jstor.org/stable/pdf/2295608.pdf. Acesso em: 17 jan. 2022.

ASANTE, M. Afrocentricity. Dr. Molefi Kete Asante, 13 abr. 2009a. Disponível em: http://www.asante.net/articles/1/afrocentricity/. Acesso em: 13 mar. 2019.

ASANTE, M. Afrocentricidade: notas sobre uma posição disciplinar. In: NASCIMENTO, E. L. (org.). Afrocentricidade: uma abordagem epistemológica inovadora. Tradução Carlos Alberto Medeiros. São Paulo: Selo Negro, 2009b. p. 93-110.

BRASIL. Resolução CNE/CEB No 4, de 8 de dezembro de 1999. Institui as Diretrizes Curriculares Nacionais para a Educação Profissional de Nível Técnico. Brasília: CNE/CEB, 1999. Disponível em: http://portal.mec.gov.br/dmdocuments/rceb004_99.pdf. Acesso em: 18 jan. 2022.

BRASIL. Lei $\mathbf{N}^{\circ}$ 9.394, de 20 de dezembro de 1996. Estabelece as diretrizes e bases da educação nacional. Brasília: Presidência da República, Casa Civil, Subchefia para Assuntos Jurídicos, [1996]. Disponível em: http://www.planalto.gov.br/ccivil_03/leis/19394.htm. Acesso em: 18 jan. 2022.

BRASIL. Lei No 10.639, de 9 de janeiro de 2003. Altera a Lei nº 9.394, de 20 de dezembro de 1996, que estabelece as diretrizes e bases da educação nacional, para incluir no currículo oficial da Rede de Ensino a obrigatoriedade da temática "História e Cultura Afro-Brasileira", e dá outras providências. Diário Oficial da União: seção 1, Brasília, DF, n. 8, p. 1, 10 jan. 2003.

BRASIL. Ministério da Educação. Diretrizes Curriculares Nacionais para a Educação das Relações Étnico-Raciais e para o Ensino de História e Cultura Afro-Brasileira e Africana. Brasília: MEC, INEP, 2004.

BRASIL. Lei No 11.645, de 10 março de 2008. Altera a Lei no 9.394, de 20 de dezembro de 1996, modificada pela Lei $\mathrm{n}^{\circ} 10.639$, de 9 de janeiro de 2003, que estabelece as diretrizes e bases da educação nacional, para incluir no currículo oficial da rede de ensino a obrigatoriedade da temática "História e Cultura Afro-Brasileira e Indígena. Diário Oficial da União: seção 1, Brasília, DF, n. 48, p. 1, 11 mar. 2008a. 
BRASIL. Lei $\mathrm{N}^{\circ}$ 11.741, de 16 de julho de 2008. Altera dispositivos da Lei $\mathrm{n}^{\circ}$ 9.394, de 20 de dezembro de 1996, que estabelece as diretrizes e bases da educação nacional, para redimensionar, institucionalizar e integrar as ações da educação profissional técnica de nível médio, da educação de jovens e adultos e da educação profissional e tecnológica. Diário Oficial da União: seção 1, Brasília, DF, n. 136, p. 5-6, 17 jul. 2008b.

BRASIL. Lei N $\mathrm{N}^{\mathrm{1}}$ 11.892, de 29 de dezembro de 2008. Institui a Rede Federal de Educação Profissional, Científica e Tecnológica, cria os Institutos Federais de Educação, Ciência e Tecnologia, e dá outras providências. Diário Oficial da União: seção 1, Brasília, DF, n. 253, p. 1., 30 dez. 2008c.

BRASIL. Um Novo Modelo em Educação Profissional e Tecnológica: Concepção de Diretrizes. Brasília: $2010 . \quad$ MEC, Disponível em: http:/ / portal.mec.gov.br/index.php?option=com_docman\&view $=$ download\&alias $=6691$-ifconcepcaoediretrizes\&Itemid=30192. Acesso em: 18 jan. 2022.

BRASIL. Resolução No 6, de 20 de setembro de 2012. Define Diretrizes Curriculares Nacionais para a Educação Profissional Técnica de Nível Médio. Diário Oficial da União: seção 1, Brasília, DF, ano 149, n. 184, p. 22, 21 set. 2012.

CIAVATTA, M. A formação integrada: a escola e o trabalho como lugares de memória e de identidade. In: RAMOS, M.; FRIGOTTO, G.; CIAVATTA, M. (org.). Ensino Médio Integrado: concepção e contradições. 3. ed. São Paulo: Cortez, 2012. p. 83-106.

CUNHA, L. Contribuição dos povos africanos para o conhecimento científico e tecnológico universal. 2005. Disponível em: http://smec.salvador.ba.gov.br/documentos/contribuicaopovos-africanos.pdf. Acesso em: 2 abr. 2019. (Texto para capacitação de professores da Rede Municipal de Salvador).

FURIÓ, C. et al. Finalidades de la enseñanza de las ciencias en la secundaria obligatoria. ¿alfabetización científica o preparación propedéutica? Enseñanza de las ciencias: revista de investigación y experiencias didácticas, v. 19, n. 3, p. 365-376, 2001.

GARCIA, N. M. D.; AUTH, M. A.; TAKAHASHI, E. K. Enfrentamentos do ensino de Física na sociedade contemporânea. São Paulo: Livraria da Física, 2016.

GOMES, N. L. Relações étnico-raciais, educação e descolonização dos currículos. Currículo sem Fronteiras, [s. l.], v. 12, n. 1, p. 98-109, jan./abr. 2003.

IFBA. Instituto Federal de Ciência, Tecnologia e Educação da Bahia. Projeto Pedagógico do Curso de Edificações do Ensino Médio Integrado ao Técnico. Eunápolis: IFBA, 2011. Disponível em: http://portal.ifba.edu.br/eunapolis/documentos-ads/plano-de-curso-edificacoesintegrado-1.pdf. Acesso em: 17 jan. 2022.

MACHADO, C. E. D. Ciência, Tecnologia e Inovação Africana e Afrodescendente. [S. l.]: [s. n.], 2014. E-book. Disponível em: http://www.bookess.com/read/19840-cienciatecnologia-einovacao-africana-e-afrodescendente/. Acesso em: 17 jan. 2022.

MORAIS, R. F. Lewis Howard Latimer e sua história aprisionada. Física na Escola, [s. 1.], v. 15, n. 2, p. 19-23, 2017. Disponível em: http://www1.fisica.org.br/fne/phocadownload/Vol15Num2/a04.pdf. Acesso em: 3 mar. 2019. 
PACHECO, E. Secretaria de Educação Profissional e Tecnológica do Ministério da Educação. Perspectivas da educação Profissional técnica de nível médio: proposta de Diretrizes Curriculares Nacionais. Brasília: SETEC/MEC, 2012.

RAMOS, M.; FRIGOTTO, G.; CIAVATTA, M. (org.). Ensino Médio Integrado: concepção e contradições. 3. ed. São Paulo: Cortez, 2012.

ROSA, K. A (pouca) presença de minorias étinico-raciais e mulheres na construção da Ciência. In: GARCIA, N. M.; AUTH, A.; TAKAHASHI, E. K. (org.). Enfrentamentos do ensino de Física na sociedade contemporânea. São Paulo: Livraria da Física, 2016. p. 620-632.

SANTOS JUNIOR, R. N. dos. Afrocentricidade e educação: os princípios gerais para um currículo afrocentrado. África e Africanidades, n. 11, nov. 2010. Disponível em: http://www.africaeafricanidades.com.br/documentos/01112010_02.pdf. Acesso em: 14 fev. 2019.

SANTOS, M. F. D.; ALEM, N. H.; DANTAS JR., J. F. O discurso do livro didático de Física: por uma escolha pela diferença. ODEERE: Revista do Programa de Pós-Graduação em Relações Étnicas e Contemporaneidade - UESB, Vitória da Conquista, v. 3, n. 6, p. 290-315, jul./dez. 2018.

SILVA, F. T. Educação das Relações Étnico-Raciais Negras no currículo da Formação de Professores. Periódico Científico Projeção e Docência, v. 5, n. 1, p. 58-69, 2014.

SILVA, M. V. D.; CORENZA, J. D. A. Currículo afrocentrado no ensino de Física: alguns apontamentos. In: CONGRESSO BRASILEIRO DE PESQUISADORES NEGROS COPENE, 10., 2018, Uberlândia. Anais eletrônicos [...]. Uberlândia: Copene, 2018. Disponível em:

https://www.copene2018.eventos.dype.com.br/resources/anais/8/1530397066_ARQUIVO_Ar tigoFinalMarcelo_JanainaCOPENE2018.pdf. Acesso em: 18 jan. 2022.

SILVA, T. T. D. Documentos de Identidade: uma introdução às teorias do currículo. 3. ed. Belo Horizonte: Autêntica, 2010.

Recebido em 10/08/2021

Versão corrigida recebida em 14/01/2022

Aceito em 15/01/2022

Publicado online em 04/02/2022

Práxis Educativa, Ponta Grossa, v. 17, e2219347, p. 1-16, 2022 